\title{
UMA POSSIBILIDADE DE RECONSTRUÇÃO DO LAÇO SOCIAL ENTRE PROFESSORES, ALUNOS E COMUNIDADE
}

\author{
POSIBILIDAD DE RECONSTRUCCIÓN DEL RELACIÓN SOCIAL ENTRE \\ PROFESORES, ESTUDIANTES Y LA COMUNIDAD
}

\section{A POSSIBILITY OF RECONSTRUCTION OF THE SOCIAL TIE BETWEEN TEACHERS, STUDENTS AND THE COMMUNITY}

RESUMO: O presente artigo é oriundo de uma atividade proposta para professores da rede pública, em um curso de formação pedagógica, onde foram produzidas narrativas individuais sobre os desafios para uma melhor aprendizagem dos alunos. De posse dessas narrativas buscamos encontrar uma característica comum capaz de promover um diálogo reflexivo. Adotamos a técnica de análise textual discursiva dando origem a três categorias: Motivação, Tecnologia digital e Aprendizagem Significativa. Identificamos nos professores um certo sentimento de isolamento, causado pela falta de interesse dos alunos e da comunidade nas atividades escolares. Concluímos apontando para relevância do pensamento e do exercício hermenêutico enquanto diálogo ético na reconstrução do laço social entre professores, alunos e comunidade.

PALAVRAS-CHAVE: Desafios na educação. Voz do professor. Hermenêutica. Análise textual discursiva.

RESUMEN: Este artículo proviene de una actividad propuesta para maestros de escuelas públicas, en un curso de capacitación pedagógica, donde se produjeron narrativas individuales sobre los desafios para un mejor aprendizaje de los estudiantes. Con estas narrativas buscamos encontrar una característica común capaz de promover un diálogo reflexivo. Adoptamos la técnica de análisis textual discursivo que da lugar a tres categorías: motivación, tecnología digital y aprendizaje significativo. Identificamos en los maestros un cierto sentimiento de aislamiento, causado por la falta de interés de los estudiantes y la comunidad en las actividades escolares. Concluimos señalando la relevancia del pensamiento hermenéutico y el ejercicio como diálogo ético en la reconstrucción del vínculo social entre docentes, estudiantes y la comunidad.

\footnotetext{
${ }^{1}$ Universidade LaSalle (UNILASALLE), Canoas - RS - Brasil. Professor e Pesquisador no Programa de PósGraduação em Educação. Doutorado em Educação (PUCRS). Bolsista de Produtividade em Pesquisa do CNPq Nível 2. ORCID: http://orcid.org/0000-0002-9059-728X. E-mail: cleber.ratto@unilasalle.edu.br

${ }^{2}$ Universidade LaSalle (UNILASALLE), Canoas - RS - Brasil. Doutorando no Programa de Pós-Graduação em Educação. Bolsista PROSUC/CAPES. ORCID: http://orcid.org/0000-0001-8117-6136. E-mail: jeferson.199810046@unilasalle.edu.br

${ }^{3}$ Universidade LaSalle (UNILASALLE), Canoas - RS - Brasil. Doutorando no Programa de Pós-Graduação em Educação. Bolsista PROSUC/CAPES. ORCID: https://orcid.org/0000-0001-5731-341X. E-mail: marceloacpereira@gmail.com
}

RIAEE - Revista Ibero-Americana de Estudos em Educação, Araraquara, v. 16, n. 2, p. 622-636, abr./jun. 2021. e-ISSN: 1982-5587 
PALABRAS CLAVE: Retos en la educación. Voz del profesor. Hermenéutica. Análisis textual discursivo.

ABSTRACT: This article comes from an activity proposed for teachers from the public network, in a pedagogical training course, where individual narratives were produced about the challenges for a better learning of students. With these narratives, we seek to find a common characteristic capable of promoting a reflective dialogue. We adopted the technique of discursive textual analysis giving rise to three categories: Motivation, Digital Technology and Meaningful Learning. We identified in teachers a certain sense of isolation, caused by the lack of interest of students and the community in school activities. We conclude by pointing to the relevance of thought and hermeneutic exercise as an ethical dialogue in the reconstruction of the social bond between teachers, students and the community.

KEYWORDS: Challenges in education. Teacher's voice. Hermeneutics. Discursive textual analysis.

\section{Introdução}

Vivemos em uma época em que está ocorrendo uma transformação acelerada dos sujeitos e dos lugares no mundo social e cultural, ocasionando uma crise de identidade, caracterizada pelas constantes mudanças estruturais, onde tradições, costumes e instituições antes estáveis são agora desafiadas por um mundo globalizado. A vida social passa a ser mediada pelo mercado global de estilos, novas tecnologias de comunicação, em um processo de desvinculação de tempos, lugares, arranjos e tradições, produzindo em alguns contextos o enfraquecimento dos laços sociais.

Diante desta acelerada transformação, a escola pública, seus professores e alunos, enfrentam desafios das mais variadas situações e contextos, gerando, em muitos casos, insegurança, desorientação, sentimento de solidão e abandono. Culminando num contexto em que uma das dificuldades enfrentadas pela escola é a falta de espaço e tempo para reflexões sobre os processos de construção e manutenção qualitativa dos vínculos sociais.

Em algumas percepções os problemas são: os alunos que perdem o interesse pelas aulas, ou as famílias que não apoiam os estudantes no processo de ensino e aprendizagem. Para os estudantes, são os conteúdos distantes de sua realidade, que não acrescentam muito em sua formação. Portanto, esses fatores se apresentam desafiadores para a escola e seus envolvidos, em um contexto que pode ser melhor compreendido na historicidade de nossa sociedade.

Segundo Sposito e Galvão (2004), o dia a dia escolar torna-se um espaço complexo de interações, com definição de identidades e singularidades. É um espaço aberto como 
comunidade de reconhecimento interpessoal, com trocas subjetivas, mas também palco de competições e conflitos que produzem, muitas vezes, situações de violência e desamparo no cotidiano escolar.

Nesse sentido, Arroyo (2014) fala de um repensar dos processos de ensino e aprendizagem, de modo a incorporar a diversidade na prática escolar, tendo como base a participação ativa de professores e alunos, promovendo uma inovação curricular. Essa passaria pelo reconhecimento de práticas inovadoras, sendo os dois grupos vistos como sujeitos da ação educativa, visto que estamos vivenciando um novo momento como escola, sendo que, segundo o autor, "somos obrigados a reconhecer a heterogeneidade, a pluralidade, as diferenças feitas tão desiguais em nossa sociedade. Um reconhecimento nada fácil em uma tradição curricular que se pautou pela homogeneidade." (ARROYO, 2014, p. 50).

É possível observar que a superação da homogeneidade demanda uma necessidade de se criar e manter condições de possibilidade para o exercício da alteridade, no sentido de prevenir um tipo de isolamento social potencialmente prejudicial ao processo educativo. Conforme destacam Dayrell e Carrano (2014, p. 125):

Diante desse desafio, a escola, bem como os diversos espaços educativos, assumem papel fundamental. Não podemos nos esquecer de que esses espaços possibilitam, entre outras coisas, a convivência com a diversidade, na qual os jovens têm a possibilidade de descobrirem-se diferentes dos outros e, principalmente, aprenderem a conviver respeitando essas diferenças. É na relação com o outro que aprendemos a reconhecer as nossas próprias limitações, a entender que não nos bastamos e que a diferença nos enriquece. Cabe ao mundo adulto criar espaços e situações por meio dos quais os jovens possam se defrontar com seus próprios limites.

Face ao apresentado, o objetivo geral deste trabalho é compreender, na perspectiva de um grupo de professores da rede pública, participantes de um curso de formação de professores, o que eles percebem como desafios para uma melhor aprendizagem dos alunos e qual pode ser o ponto de partida coletivo para se trabalhar qualitativamente esses desafios.

Para esta tarefa, buscamos encontrar nas narrativas alguma característica geral que pudesse contextualizar em uma mesma direção as percepções apresentadas pelos professores quanto aos desafios da escola na produção de um ambiente para melhor aprendizagem. Procuramos por uma característica que pudesse servir de base para um diálogo reflexivo capaz de conectar as narrativas em torno de um mesmo objetivo, fácil de ser reconhecido coletivamente pelo grupo. 


\section{Caminhos percorridos}

O corpus de análise desta pesquisa, de cunho qualitativo (GIL, 2010), é composto de respostas abertas de uma turma de professores atuantes em escolas da rede pública que participaram de um curso de formação pedagógica para professores disponibilizado pelo Consórcio das Universidades Comunitárias Gaúchas - Comung - na modalidade a distância.

O curso, dividido em 3 eixos temáticos, abarcou os temas: aprendizagem; organização, planejamento e acompanhamento da ação pedagógica e avaliação. Dentro do Eixo I do respectivo curso, foram utilizadas as respostas dos professores, cujas identidades são mantidas em sigilo, em um exercício em que se pede que eles criem um enunciado e apresentam brevemente um desafio geral do processo de aprendizagem.

Para a análise dos dados, foi utilizada a técnica de análise textual discursiva, a qual tem por finalidade a elaboração de metatextos a partir de um processo de unitarização, desconstrução e categorização de discursos, segundo a premissa de Moraes e Galiazzi (2007). Neste primeiro momento, todas as 21 respostas foram agrupadas em um único texto, o que se constituiu em um processo de unitarização. Posteriormente a esse passo, foram realizadas leituras, de forma a propiciar o surgimento de novas categorias, por meio de palavras que contivessem sentidos semelhantes das falas dos professores. Com isso, emergiram as seguintes categorias que auxiliaram na análise hermenêutica para ao objetivo de pesquisa: Motivação; Tecnologia digital; e, Aprendizagem Significativa.

Essas categorias mencionadas serão desconstruídas na próxima parte: análise dos dados, onde as falas dos professores são citadas em itálico e referidas como Professor + numeral (ex. Professor 1), explicando como foram agrupadas, entremeando com referencial teórico, quando possível. A importância de se aplicar um processo de categorização, nesse aspecto, é evidenciada pelo fato de permitir enfatizar:

[...] a interpretação, a subjetividade e intersubjetividade, de valorização dos contextos de produção e da natureza histórica dos processos de constituição de significados. Ainda que o encaminhamento das análises possa também pretender características mais objetivas e dedutivas, é na vertente mais subjetiva e indutiva que se atingem resultados mais criativos e originais (MORAES; GALIAZZI, 2007, p. 79).

Uma característica relevante do método de análise textual discursiva é sua aparente aproximação com a hermenêutica proposta por Gadamer (2015), onde a compreensão ocorre na fusão do horizonte do texto com o horizonte do interlocutor, ficando evidente que: 
[...] não se pode falar de fins bem estabelecidos na investigação das ciências do espírito como se dá nas ciências da natureza, onde a investigação penetra cada vez mais profundamente na natureza. Nas ciências do espírito o interesse do investigador que se volta para a tradição é motivado, de maneira especial, pelo respectivo presente e seus interesses. É só pela motivação do questionamento que se estabelece o tema e o objeto de investigação. Com isso, a investigação histórica se sustenta no movimento histórico em que se encontra a própria vida, e não se deixa compreender teleologicamente a partir do objeto a que se orienta a investigação. Em si, um tal objeto não existe de modo algum. É isso o que distingue as ciências do espírito das da natureza (GADAMER, 2015, p. 377-378).

Um certo caráter hermenêutico atribuído ao método de análise textual discursiva pode ser evidenciado ao considerarmos que o método propõe, entre outras coisas, o impacto da linguagem na percepção e construção de mundos, a valorização do outro no processo interpretativo, bem como a ideia de (re)construção teórica constituída no que emerge da experiência fenomenológica com os participantes da pesquisa.

É nessa direção que compreendemos que o:

[...] processo da análise textual discursiva tem fundamentos na fenomenologia e na hermenêutica. Valoriza os sujeitos em seus modos de expressão dos fenômenos. Centra sua procura em redes coletivas de significados construídos subjetivamente e que o pesquisador se desafia a compreender, descrever e interpretar. São processos hermenêuticos. (MORAES; GALIAZZI, 2007, p. 169).

Assim, esse modo de análise tem sua inserção na análise qualitativa e no paradigma interpretativo fenomenológico-hermenêutico (Bicudo, 2011). Nesse sentido, entendemos que a escolha do método de análise textual discursiva é relevante na medida em que este trabalho se propõe como um possível exercício hermenêutico.

No percurso escolhido para este trabalho organizamos em três categorias as respostas dos professores, que se constituirão em "vozes" desses sujeitos da atividade docente, segundo demonstra o Quadro 1.

Quadro 1 - As categorias emergentes

\begin{tabular}{|c|c|}
\hline Categoria & Embasamento \\
\hline Motivação & $\begin{array}{l}\text { Essa categoria agrega respostas que contenham reflexões, opiniões, e } \\
\text { críticas sobre as relações entre o aluno e o professor, o aluno e o seu interesse } \\
\text { para com o seu estudo e a participação da família no desenvolvimento } \\
\text { educacional do aluno. Ela emergiu de } 6 \text { respostas que continham esses } \\
\text { sentidos. }\end{array}$ \\
\hline Tecnologia digital & Categoria a qual obteve maior relevância nas respostas dos \\
\hline
\end{tabular}

RIAEE - Revista Ibero-Americana de Estudos em Educação, Araraquara, v. 16, n. 2, p. 622-636, abr.jun. 2021. e-ISSN: 1982-5587 


\begin{tabular}{|c|l|}
\hline & $\begin{array}{l}\text { professores (12 respostas), que abarcam sentidos onde os professores expressas } \\
\text { críticas e reflexões nas relações com as novas tecnologias digitais, sejam } \\
\text { aplicadas em aula ou mídias sociais, assim como na interferência destas na } \\
\text { relação professor-aluno. }\end{array}$ \\
\hline $\begin{array}{c}\text { Aprendizagem } \\
\text { Significativa }\end{array}$ & $\begin{array}{l}\text { Essa última categoria, por fim, contém apenas 2 respostas com } \\
\text { sentidos que remetem à ação docente, no sentido de reconhecimento do donte enquanto sujeito possuidor de conhecimentos, assim como na } \\
\text { pertinência dos conteúdos ensinados. }\end{array}$ \\
\hline
\end{tabular}

Fonte: Elaborado pelos autores

\section{A crise da motivação nas narrativas dos professores}

No Quadro 1, organizamos três categorias e os seus embasamentos, considerando a escala de representatividade que estas tiveram nas falas dos professores. Em um sentido geral, foi possível observar nas narrativas que a prática educativa perpassa simbolicamente por três contextos; Intenção, ambiente e resultado. Na intenção encontramos a motivação, no ambiente surgiu a tecnologia digital e no resultado se consolidou a ideia de uma aprendizagem significativa.

Entendemos que a motivação é o que dá sentido ao interesse, perpassa por todas as relações sociais e contextos que implicam uma ação humana. Sob esta perspectiva, é pela motivação que o interesse se manifesta e os valores se consolidam, promovendo interações sociais em menor ou maior grau de qualidade, vínculos. Em muitos aspectos a motivação é a força que une ou separa as pessoas em torno de algum objetivo, como por exemplo, o de ensinar e aprender. Nessa perspectiva, os professores relataram a manutenção do interesse e valorização da educação, como um dos desafios no cotidiano da escola pública.

Segundo o Professor 1:

Falta de disciplina e respeito dos alunos com os professores: com a decadência que se encontra a educação na nossa atualidade, encontramos muitas dificuldades com a falta de disciplina e respeito dos alunos com os professores, tornando-se cada dia mais difícil para o professor contornar essa situação, pois na maioria dos casos, essas atitudes e linguagem utilizada, fazem parte do cotidiano familiar (Resposta do Professor 1).

A resposta do professor carrega críticas quanto a relação da sociedade e a educação, com ênfase na disciplina, onde os professores são desrespeitados pelos estudantes, o que se pode inferir ser uma situação constante. Vai no mesmo sentido a fala do Professor 6, que aponta que os alunos não conseguem mais se concentrar em sala de aula e que "muitos vão à 
escola por obrigação[...], tornando-se cada dia mais violentos [...] perturbando o ambiente escolar" (Resposta do professor 6).

Outro aspecto que também aparece nessa categoria é a participação dos atores deste contexto educacional, tanto alunos quanto família. O Professor 10 afirma que a educação infantil é vista como assistencialista, sendo que falta interesse da família em participar ativamente do processo de aprendizagem dos filhos. $\mathrm{O}$ mesmo sentido aparece na resposta do Professor 17, ao afirmar que "falta estímulo em casa", alegando que as famílias compreendem a escola como um local de cuidado com as crianças, não se envolvendo com o aprendizado dos filhos.

Por fim, o Professor 15 destaca outro aspecto inserido na categoria motivação. Em sua fala, aparece a preocupação com alunos com dificuldades específicas de aprendizagem, como déficit de atenção, dislexia etc., os quais precisam de acompanhamento externo, nem sempre disponível. Essa preocupação denota o interesse do professor com a qualidade do seu trabalho docente, ao considerar um acolhimento mais justo para os alunos com dificuldades extras em seu percurso educacional.

Uma questão que nos pareceu central ao compor a categoria Motivação foi um certo sentido de solidão e abandono, presente nas narrativas dos professores, em especial ao observarmos que as constatações fazem referência, em grande medida, a uma falta de parceria entre educadores, alunos e familiares. Em várias narrativas observadas, cada uma ao seu modo, sinaliza para a existência de uma carência de envolvimento social, acarretando um sentimento de esquecimento, em especial, pela falta de interesse dos alunos e familiares em participar de forma solidária nas demandas da vida escolar.

Nesse sentido, foi possível observar um certo lamento que aponta para um tipo de "cultura da solidão", uma vez que o "isolamento docente tem raízes em fatores como a arquitetura das escolas, a estrutura dos seus horários, a sobrecarga de trabalho e a própria história da profissão docente" (DAMIANI, 2008, p. 219).

Em dados obtidos pela QEdu na pesquisa Prova Brasil em 2018, 93\% dos professores afirmaram existir uma falta de assistência e acompanhamento dos pais na vida escolar dos alunos. E $60 \%$ dos professores relataram participar de alguma atividade com outros professores, como por exemplo, trabalho interdisciplinar, em uma média abaixo de três vezes ao ano. Essa perspectiva de pouca interação com os pares e familiares parece provocar, em alguns casos, inseguranças, frustrações e decepções com a própria atividade docente.

Huberman segue nessa direção quando afirma que:

RIAEE - Revista Ibero-Americana de Estudos em Educação, Araraquara, v. 16, n. 2, p. 622-636, abr./jun. 2021. e-ISSN: 1982-5587 
O isolamento alimenta a insegurança continuada sobre a capacidade pedagógica porque o trabalho de cada um é feito sozinho, nunca sujeito a um escrutínio exterior dando origem a imagens fantásticas de outros professores muito melhores a trabalharem noutras salas de aula ou escolas (HUBERMAN 1993, p. 31).

$\mathrm{Na}$ perspectiva de Honneth (2003, p. 209), a autorrealização social perpassa necessariamente por um sentimento de pertencimento de grupo, onde o "[...] indivíduo se sabe aí como membro de um grupo que está em condições de realizações comuns, cujo valor para a sociedade é reconhecido por todos os seus demais membros". Nesse sentido, além do sentimento de insegurança, é possível ponderar que um isolamento social, como este narrado pelos professores, pode em algum momento acarretar um forte sentimento de ausência de reconhecimento social, comprometendo nestes casos a própria autoestima do professor. Essa realidade docente pode de diferentes formas - por insegurança ou conflitos de autoestima afetar o desempenho e a própria saúde deste profissional.

Segundo Honneth (2003), as relações sociais pautadas numa relação de solidariedade, colaboração mútua, promovem autoestima e com ela uma autorrealização social. No entanto, para diluir em alguma medida essa "cultura da solidão" apontada na fala dos professores, será necessário alterar, em algum momento, modos de se pensar e existir, uma vez que:

Para que os professores ressignifiquem a sua prática é preciso que a teorizem. E este movimento de teorizar a prática não se efetiva somente com treinamentos, palestras, seminários, aulas expositivas, mas muito mais, quando há uma relação dinâmica com a prática deste professor a partir de uma reflexão coletiva, auto-reflexão, pensamento crítico e criativo, via educação continuada. É preciso desencadear estratégias de formação processuais, coletivas, dinâmicas e contínuas. Refletir com os demais professores e compartilhar erros e acertos, negociar significados e confrontar pontos de vista surge como algo estimulador para uma prática pedagógica comprometida (RAUSCH; SCHLINDWEIN, 2001, p. 121).

Um bom ponto de partida, com potencial de diluir essa "cultura da solidão" parece ser a prática do diálogo comprometido com um exercício hermenêutico. Nesse sentido, "O diálogo hermenêutico acontece na relação entre parceiros, e não entre espectadores passivos ou interlocutores indiferentes" (ROHDEN, 2004, p. 194), produzindo pertencimento de grupo e um real reconhecimento intersubjetivo, mútuo e ético.

No entanto, é preciso ficar atento às tecnologias digitais, também conhecidas como tecnologias da informação: estas ocupam um lugar de destaque na medida em que influenciam os jovens em uma dada direção, motivando muitas vezes ações contrárias ao processo 
educativo, podendo em certos contextos dificultar ou favorecer uma dada proposta de característica hermenêutica.

\section{Os impasses da Tecnologia digital no ambiente escolar}

O ambiente da escola, enquanto espaço e estrutura que oferece os meios por onde as relações se configuram, facilitando ou dificultando as motivações para o ensino e aprendizado tem, na perspectiva dos professores, impasses que precisam ser debatidos e encarados com seriedade. Entre eles, se destaca a ascensão acelerada das tecnologias digitais na sociedade, alterando os modos de se perceber a escola e os métodos educativos. Nesse sentido, uma das preocupações sobre as tecnologias digitais é que elas carregam em si um potencial de dispersão e distanciamento dos afazeres necessários ao aprendizado.

Segundo o Professor 2:

Os alunos hoje têm acesso a muitas informações que chegam por meio das mídias digitais, sendo estas muito rápidas e sem aprofundamento. Para o professor acaba sendo muito dificil incentivar a leitura de livros, artigos ou textos mais aprofundados, pois os alunos têm preguiça de ler e por isso acabam com dificuldade de interpretar, abstrair, o que os distancia cada vez mais da leitura (Resposta do Professor 2).

Percebemos na fala do professor 2 o aparente paradoxo leitura e mídias digitais. Apesar de essas mídias requererem leitura, o professor não vislumbra a possibilidade de aprofundamento e/ou utilização dessas informações para a aula, o que se assemelha a um paradigma, onde o professor tem uma estrutura de pensamento ainda centrada no ensino tradicional, sendo a tecnologia digital uma barreira a essa estrutura.

No mesmo sentido verificamos nas respostas dos Professores: 4, que critica o uso de celulares em sala de aula; 7, que afirma que as tecnologias digitais despertam mais atenção que a escola; e 8, que fala sobre a dificuldade de fazer os alunos lerem livros para aulas de língua portuguesa. Outra fala importante, que merece destaque, é do Professor 12, que vai também ao encontro do Professor 2:

O que fazer com o desinteresse ou falta de entendimento dos alunos em aulas que para eles são tão sem graça e sem lógica: tudo parece ser banal aos olhos de quem tem a tecnologia e mídias diversas ao alcance das mãos. Mesmo uma criança que não está alfabetizada já sabe procurar jogos, vídeos e outras formas entretenimento nas redes sociais, porém se é escrito num quadro verde não reconhece as mesmas letras as quais digita em um celular ou tablet. Com certeza a escola vive na contramão da tecnologia, pois ainda vive no passado retrógrado e obsoleto de quadro, giz e um

RIAEE - Revista Ibero-Americana de Estudos em Educação, Araraquara, v. 16, n. 2, p. 622-636, abr./jun. 2021. e-ISSN: 1982-5587 
professor que por melhor vontade que tenha, acaba desmotivado vivenciando essa realidade de apatia de alunos "alienados", os chamados analfabetos funcionais, que hoje são a grande maioria dos alunos atuais e os já formados pelas nossas escolas recentemente (Resposta do Professor 12).

Podemos observar na fala do professor duras críticas ao contexto educacional em geral e sua relação com a tecnologia digital, onde a escola não acompanhou o ritmo das mudanças tecnológicas, gerando alunos desinteressados e de formação inadequada. A fala também traz aspectos didáticos preocupantes, como a alfabetização digital, onde o aluno reconhece letras em formato digital e não consegue visualizá-las em outro meio físico.

O desafio apresentado pelo Professor 12 também é partilhado pelo Professor 14, o qual alerta para a necessidade de suporte pedagógico para uso da tecnologia digital na Educação Infantil.

Outras críticas, mesmo que indiretas, provém dos Professores: 16, que fala sobre o ensinar na era do imediatismo, onde a velocidade ditada pela tecnologia digital compromete o interesse e a aprendizagem dos alunos para com os conteúdos; 19, que além da informatização e redes sociais, traz os recursos audiovisuais como facilitadores que estimulam a falta de interesse dos alunos para a leitura.

O ponto de inflexão para "desafios positivos" na categoria tecnologia digital na voz dos professores parte da avaliação do Professor 21, que afirma que "a falta de interesse dos alunos é devido a um conteúdo entediante e sem criatividade apresentado pelos educadores [...]" o qual deve em sua opinião ser ensinado de forma que aguce o aluno a querer saber mais.

Uma fala importante, nesse sentido, vem do Professor 13:

Os alunos estão inseridos no mundo da era digital e o grande desafio para o professor nos dias atuais é fazer desta ferramenta (tecnológica) um grande aliado, no sentido de que o aluno possa usufruir da melhor maneira possivel desta ferramenta que veio para transformar o mundo. Mas acredito que o professor precisa saber usar isto a seu favor. Para que os alunos sejam capazes de fazer uso destas tecnologias da melhor maneira possivel (Resposta do Professor 13).

Para o Professor 13, a tecnologia digital deve ser uma aliada, dentro da noção de que todos estão inseridos na "era digital". Essa fala traz em si uma visão otimista da educação e uma crítica. A crítica pode ser percebida na necessidade de o professor se atualizar e utilizar a tecnologia digital em aula, ao contrário do que se percebe nas críticas e desafios apontados no início desta categoria. Essa fala pode ser complementada pelo apontamento do Professor 5, 
que reflete sobre o uso das tecnologias digitais nas aulas de matemática, onde sugere o uso de softwares para que os alunos visualizem e entendam melhor o conteúdo.

Por fim, nessa categoria, apresenta-se uma sugestão do Professor 9, que afirma que a "junção do tradicional com o tecnológico é uma boa solução", visto que a mescla de tecnologias digitais desperta o interesse dos alunos. Para ele, cabe ao professor se atualizar quanto às mídias para fazer uso, visto que estão presentes na vida de todos.

Mesmo entre aqueles que apoiam o uso das tecnologias na educação, surgiu em algumas narrativas um certo desconforto com a constante e talvez excessiva presença tecnológica na vida dos alunos. Ao que parece, a tecnologia concorre com a educação na medida em que seduz os alunos com a promessa de facilidades que dificultam a construção de certas competências, como a leitura mais aprofundada e a manutenção do foco e do interesse.

Nesse sentido, a resposta para a pergunta se é possível integrar tecnologia e educação parece distante de um consenso, dúvidas existem. No entanto, há concordância sobre a acelerada ascensão e a necessidade do uso tecnológico na atividade escolar, tanto pela atratividade e interesse despertado junto aos jovens, como pela possibilidade de novas formas qualitativas de aplicação pedagógica.

Em um sentido geral, nas narrativas apresentadas, as desconfianças sobre a integração da tecnologia na educação pública ocorre motivada pela percepção da complexidade da acelerada manutenção própria do contexto tecnológico e de uma já conhecida dificuldade, relacionada com investimentos em capacitações e necessidade de mudança de atitude na gestão pública, relacionada com a forma de se pensar a escola e sua arquitetura.

Para os professores, segundo observado em suas narrativas, é importante que se tenha clareza do uso e impacto tecnológico, uma vez que:

[...] por mais potentes que sejam os computadores ou por mais velozes que sejam as redes de transmissão, não irão acabar com todos os problemas que envolvem a questão da inserção de tecnologias na educação, pois as tecnologias têm implicações políticas, econômicas, sociais e culturais que precisam ser observadas com a maior atenção quando introduzidas em espaços educativos (BIANCHI; PIRES; VANZIN, 2008, p. 55).

No âmbito das tecnologias, foi possível observar que alguns professores se sentem sozinhos, desamparados sobre onde e com quem dialogar quando se precisa entender os impactos e estratégias de uso didático das novas tecnologias digitais. As dúvidas e inseguranças surgem motivadas pelas distintas e complexas situações das salas de aula em múltiplos contextos socioculturais, que precisam, de uma ou outra forma, produzir no aluno uma aprendizagem significativa.

RIAEE - Revista Ibero-Americana de Estudos em Educação, Araraquara, v. 16, n. 2, p. 622-636, abr./jun. 2021. e-ISSN: 1982-5587 


\title{
Os desafios para uma Aprendizagem Significativa
}

A ideia, em sentido geral, de uma aprendizagem significativa, coloca no centro da questão a interação entre os saberes antigos e novos, em uma relação fundamentalmente hermenêutica. Em especial, pelo reconhecimento de ser o conhecimento uma construção sempre interpretada na ressignificação de valores históricos e culturalmente construídos no interior de uma dada subjetividade.

Neste sentido, as condições de aprendizagem dependem de um reconhecimento mútuo da realidade do aluno e do professor, no intuito de possibilitar um diálogo capaz de integrar o conhecimento anterior do aluno com aquele que se pretende apresentar, algo que implica necessariamente numa relação ética capaz de produzir confiança e acolhimento. É nessa direção que sinaliza o professor 11:

\begin{abstract}
Relação professor x aluno: É necessário que o professor compreenda que sua relação com seus alunos é papel fundamental no processo de ensinoaprendizagem. Respeitar os saberes prévios de seus alunos, estar disponivel para o diálogo, etc. são condições que tornam favoráveis a relação professor X aluno e com isso todos saem ganhando. Considerar o aluno uma 'tábula rasa' vem na contramão da educação justa e igualitária que tanto sonhamos. Construir os saberes a partir daquilo que o aluno nos traz auxilia no processo de aprendizagem. O aluno aprende melhor quando sabe que seu professor gosta dele. (Resposta do Professor 11).
\end{abstract}

A partir da fala do Professor 11, verificamos um componente básico do conceito de aprendizagem significativa de Ausubel (2003), que postula que a aprendizagem na sala de aula se refere a processos de aquisição, retenção e utilização de conjuntos de informações significativas, como fatos, proposições, princípios e termos de disciplinas, cujas informações podem ser matérias e conteúdos organizados em determinada área na qual o indivíduo detém conhecimento prévio. Ao não considerar o aluno uma "tábula rasa" e valorizar seu conhecimento para o processo de ensino e aprendizagem, o professor converge para esta teoria de aprendizagem.

Ao encontro desta fala, o Professor 18 afirma que o desinteresse dos alunos é motivado pelos conteúdos ensinados. $\mathrm{Na}$ ótica dos estudantes, os conteúdos não têm influência em suas vidas e não atendem suas necessidades, o que resulta em desinteresse, interações agressivas entre seus colegas, e até agressões verbais e físicas com professores.

Para o professor 20, que utiliza a Educação Infantil como exemplo de aprendizagem significativa, é importante não se esquecer que essa perspectiva exige uma proposta mais 
"criativa e menos tradicional, capaz de produzir um interesse desafiador no aluno" (Resposta do Professor 20).

Essa percepção da necessidade de mudança da estratégia em relação ao como pensar a escola, também apareceu em narrativas sobre a aprendizagem significativa. Em especial, quanto ao distanciamento das disciplinas em relação à realidade do aluno. As narrativas da categoria aprendizagem significativa, ainda que pareçam distintas daquelas observadas na categoria Motivação e Tecnologia digital, estão nitidamente centradas por um distanciamento sistêmico, onde algumas necessidades do aluno não são reconhecidas ou valorizadas em seu contexto, proporcionando, ao que parece, a possibilidade de uma escola pouco conectada com as expectativas e demandas socioculturais dos alunos, produzindo o enfraquecimento dos laços sociais com a comunidade e discentes.

\section{Considerações finais}

Buscamos encontrar em algumas narrativas de professores de escola pública um ponto motivador em comum, capaz de possibilitar uma certa unidade de sentido com o objetivo de compreender, na perspectiva desse grupo, o que eles percebem como desafios para a aprendizagem dos alunos.

Ao organizarmos as narrativas nas respectivas categorias, nos pareceu que o principal fenômeno que potencializa a insegurança e conflitos de autoestima nos professores e alunos, dificultando as relações sociais na escola, é um dado sentimento de isolamento, quase sempre motivado pela ausência de ações que promovam com maior clareza uma valorização social dos professores e alunos da rede pública. Sem um reconhecimento social ético, fica difícil a manutenção de um ambiente capaz de produzir um sentimento de pertencimento, amparo e autoestima.

Tal perspectiva permite ponderarmos sobre a importância do pensamento e do exercício hermenêutico enquanto diálogo e fundamento para reconstrução do laço social, onde o movimento de reconhecimento mútuo intersubjetivo, capaz de proporcionar segurança e autoestima, perpassa necessariamente pela alteridade, atenção ao outro, que é facilmente identificada na interação pautada por um diálogo ético, sem pretensão de conclusões finais, mas provisórias, em uma postura que é própria da solidariedade.

Diante do que foi apresentado, é possível ponderar que um primeiro passo para se iniciar uma diluição das dificuldades apontadas nas narrativas dos professores consiste numa disposição para um diálogo ético, em caráter hermenêutico, proporcionado ações na direção 
de uma prática efetiva de reconhecimento mútuo e valorização social dos envolvidos, numa proposta de alteridade.

AGRADECIMENTOS: O presente trabalho foi realizado com apoio da Coordenação de Aperfeiçoamento de Pessoal de Nível Superior - Brasil (CAPES) - Código de Financiamento 001 .

\section{REFERÊNCIAS}

ARROYO, M. Repensar o Ensino Médio. Por quê? In: DAYRELL, J.; CARRANO, P.; MAIA, C. L. (Org.). Juventude e ensino médio. Belo Horizonte: Editora UFMG, 2014. p. 55-73.

AUSUBEL, D. P. Aquisição e retenção de conhecimentos: uma perspectiva cognitiva. 1. ed. Lisboa: Paralelo Editora, 2003. p. 219.

BIANCHI, P; PIRES, G. L.; VANZIN, T. As tecnologias de informação e comunicação na rede municipal de ensino de Florianópolis: possibilidades para a educação (física). Revista Linhas, Florianópolis, v. 9, n. 2, p. 56-75, jul./dez. 2008.

BICUDO, M. A. V. Pesquisa qualitativa segundo a visão fenomenológica. 1. ed. São Paulo: Cortez, 2011. p.150.

DAMIANI, M. F. Entendendo o trabalho colaborativo em educação e revelando seus benefícios. Educ. rev., Curitiba, n. 31, p. 213-230, 2008. DOI: https://doi.org/10.1590/S010440602008000100013

DAYRELL, J.; CARRANO, P. Juventude e ensino médio: quem é este aluno que chega à escola. In: DAYRELL, J.; CARRANO, P.; MAIA, C. L. (Org.). Juventude e ensino médio. Belo Horizonte: Editora UFMG, 2014. p. 101-133.

GADAMER, H. G. Verdade e método I: traços fundamentais de uma hermenêutica filosófica. 15. ed. Petrópolis: Editora Vozes, 2015. p. 632.

GIL, A. C. Como elaborar projetos de pesquisa. 5 ed. São Paulo: Editora Atlas S.A., 2010. p. 175.

HONNETH, A. Luta por reconhecimento: a gramática dos conflitos morais. São Paulo: Ed 34. 2003.

HUBERMAN, M. The lives of teachers. New York: Teachers College Press, Columbia University, 1993. p. 148.

MORAES, R.; GALIAZZI, M. C. Análise textual discursiva. Ijuí: UNIJUÍ, 2007. p. 224. 
RAUSC, R. B.; SCHLINDWEIN, L. M. As ressignificações do pensar/fazer de um grupo de professoras das séries iniciais. Contrapontos, Itajaí, v. 1, n. 2, p. 109-23, 2001.

ROHDEN, L. Hermenêutica filosófica: uma configuração entre a amizade aristotélica e a dialética dialógica. Síntese, v. 31, n. 100, p. 191-212, 2004. DOI:

https://doi.org/10.20911/21769389v31n100p191-212/2004

SPOSITO, M. P.; GALVÃO, I. A experiência e as percepções de jovens na vida escolar na encruzilhada das aprendizagens; o conhecimento, a indisciplina, a violência. Perspectiva, Florianópolis, v. 22, n. 02, p. 345-380, jul./dez. 2004.

\section{Como referenciar este artigo}

RATTO, C. G.; SILVA, J. L.; PEREIRA, M. A. C. Uma possibilidade de reconstrução do laço social entre professores, alunos e comunidade. Revista Ibero-Americana de Estudos em Educação, Araraquara, v. 16, n. 2, p. 622-636, abr./jun. 2021. e-ISSN: 1982-5587. DOI: https://doi.org/10.21723/riaee.v16i2.12969

Submetido em: 28/09/2019

Revisões requeridas em: 10/06/2020

Aprovado em: $15 / 10 / 2020$

Publicado em: 01/02/2021 